\title{
Fish-isolated Naegleria strains and their phylogeny inferred from ITS and SSU rDNA sequences
}

\author{
Iva Dyková ${ }^{1,2}$, Hana Pecková $^{1}$, Ivan Fiala $^{1,2}$ and Helena Dvořáková ${ }^{1}$ \\ ${ }^{1}$ Institute of Parasitology, Biology Centre, Academy of Sciences of the Czech Republic, Branišovská 31, 37005 České \\ Budějovice, Czech Republic; \\ ${ }^{2}$ Faculty of Biological Sciences, University of South Bohemia, Branišovská 31, 37005 České Budějovice, Czech Republic
}

Key words: Naegleria, fish-isolated strains, SSU rDNA, ITS, phylogeny, taxonomy

\begin{abstract}
Effort was made to identify Naegleria strains isolated from organs of fish, using phylogenetic analyses of SSU rDNA and ITS sequences. Eighteen fish-isolated strains studied enlarged substantially the so far available set of Naegleria strains characterized by both molecular markers. The phylogenetic analyses of separate and concatenated SSU rDNA and ITS sequences revealed phylogenetic relationships of strains under study; however, they failed to solve classification of fish-isolated strains into species. The sequence similarity of strain-representatives of Naegleria species as well as data obtained on intragenomic variation of ITS sequences discouraged the authors from the definition of new species. The results of the present study provide evidence of a need to re-evaluate the current practice of setting boundaries between species of the genus Naegleria. Sequences obtained in this study have been deposited in GenBank with accession numbers DQ768714-DQ768743.
\end{abstract}

The biomedical importance of free-living amoebae of the genus Naegleria Alexeieff, 1912 has been widely recognized and stressed in many original papers published in the field. The research history and the development of methods to identify strains and species of the genus were detailed in a comprehensive review article by De Jonckheere (2002). In this, as well as in a following paper, De Jonckheere (2004) noted that with the exception of the pathogenic species $N$. fowleri, very little had been known about the degree of variation within individual Naegleria species and that there had been still many species represented by one strain only. He called for comparison of more isolates of different origin. The summary of data available on the type and other Naegleria strains representing 40 species of the genus recorded to date (Table 1) clearly shows that definitions of individual species are based on different molecular markers. Sequences of the small subunit of the nuclear ribosomal DNA (SSU rDNA) and internal transcribed spacer (ITS) are known for approximately one half of the named Naegleria species. Other species were defined using sequences of the ITS region only.

Our first screening for the presence of free-living amoebae in organs of fish resulted in isolation of 18 Naegleria strains. Six of them were subjected to sequence and riboprinting analyses of SSU rRNA genes (Dyková et al. 2001, Dyková and Lom, 2004). Phylogenetic analyses resulted in identification of one strain from the brain of a fish with Naegleria australiensis and another five strains as closely related to $N$. clarki.

Since ITS sequences have been introduced as a tool to resolve phylogenetic relationships between closely related Naegleria species and 11 new species have been recently defined using this tool (De Jonckheere 2004), we have decided to subject a new set of Naegleria strains of fish origin to sequencing of both SSU rDNA and ITS and to compare the results of their phylogenetic analyses.

\section{MATERIALS AND METHODS}

\section{Strain origin, culturing and morphological studies}

Fish-isolated Naegleria strains used in the study are listed in Table 2 along with details of their origin. Cryopreserved clonal cultures of these strains have been stored in the culture collection maintained in the Institute of Parasitology (Biology Centre, Academy of Sciences of the Czech Republic).

The assemblage of Naegleria strains included in the study consists of 12 novel and 6 strains that were partly characterized in a previous study (Dyková et al. 2001). Except for two strains (CL/I and RR13Z/I) cultured in Bacto Casitone medium enriched with calf serum and antibiotics and changed every other day (Červa 1969), all other strains were grown on non-nutrient agar supplemented with malt and yeast extracts $(0.1 \mathrm{~g}$ of each per litre) that, together with the bacteria brought by individual cell populations to cultures, served as a food supply. The growth of bacteria and amoebae was balanced during a long period of subculturing.

Clonal cultures of individual strains (maintained at $20^{\circ} \mathrm{C}$ and subcultured once a week) were used for light microscopic and ultrastructural observations as well as DNA extractions. The maximum temperature limit for culture growth was determined by incubation at $30^{\circ} \mathrm{C}$ and $37^{\circ} \mathrm{C}$. A single attempt was made to establish the influence of low temperature.

Hanging drop preparations and standard light microscopy approaches, including translucent light and Nomarski differential interference contrast (DIC), were used to characterise and

Address for correspondence: I. Dyková, Institute of Parasitology, Biology Centre, Academy of Sciences of the Czech Republic, Branišovská 31, 37005 České Budějovice, Czech Republic. Phone: ++420 387775 423; Fax: ++420 385 310 388; E-mail: iva@paru.cas.cz 
Table 1. Naegleria strains assigned to defined species and their molecular characteristics available to date. Species with authorships are listed below the table. Shaded areas indicate the sequences that were used to identify the respective amoebae.

\begin{tabular}{|c|c|c|c|c|c|c|c|c|c|}
\hline Naegleria species & Strain & $\begin{array}{c}\text { SSU } \\
\text { rDNA }\end{array}$ & ITS & Intron & Naegleria species & Strain & $\begin{array}{c}\text { SSU } \\
\text { rDNA }\end{array}$ & ITS & Intron \\
\hline N. americana & CCAP1518/1G & & & & N. fultoni & NG885 & & & \\
\hline \multirow{2}{*}{ N. andersoni } & A2 & & & & N. galeacystis & AV500 & & & \\
\hline & PPMFB-6 & & & & N. gallica & Capd60 & & & \\
\hline N. angularis & T692 & & & & \multirow[t]{2}{*}{ N. gruberi } & NEG-M & & & \\
\hline N. antarctica & NG409 & & & & & AUD1 & & & \\
\hline \multirow{6}{*}{ N. australiensis } & TT & & & & N. italica & AB-T-F3 & & & \\
\hline & Yodo5 & & & & $N$. indonesiensis & NG945 & & & \\
\hline & Yodo6 & & & & $N$. jadini & 0400 & & & \\
\hline & PP397 & & & & N. jamiesoni & T56E & & & \\
\hline & LSR34 & & & & \multirow[t]{2}{*}{ N. johanseni } & NG874 & & & \\
\hline & $\mathrm{CB} 2 \mathrm{~B} / \mathrm{I}$ & & & & & NG927 & & & \\
\hline N. byersi & NG597 & & & & $N$. laresi & EDF147 & & & \\
\hline N. canariensis & TE1(37) & & & & \multirow{3}{*}{ N. lovaniensis } & $\mathrm{Aq} / 9 / 1 / 45 \mathrm{D}$ & & & \\
\hline N. carteri & NG055 & & & & & F9 & & & \\
\hline N. chilensis & NG946 & & & & & C-0490 & & & \\
\hline \multirow{8}{*}{ N. clarki } & Pd56Z/I & & & & N. martinezi & NG872 & & & \\
\hline & Pd72Z/I & & & & N. mexicana & Mx6J & & & \\
\hline & $4709 / \mathrm{I}$ & & & & N. minor & WTO43 & & & \\
\hline & $4564 / \mathrm{IV}$ & & & & N. morganensis & NG236 & & & \\
\hline & $4177 / \mathrm{I}$ & & & & N. niuginiensis & NG427 & & & \\
\hline & BG6 & & & & N. pagei & CCAP1518/1E & & & \\
\hline & RU30 & & & & N. peruana* & $\mathrm{N} 280$ & & & \\
\hline & RU42 & & & & \multirow{3}{*}{ N. philippinensis** } & NG206 & & & \\
\hline N. dobsoni & NG257 & & & & & RJTM & & & \\
\hline N. dunnebackei & CDCV419 & & & & & RITM-1 & & & \\
\hline N. endoi & EDF6 & & & & \multirow{2}{*}{ N. pringsheimi } & CCAP1518/1D & & & \\
\hline \multirow{9}{*}{ N. fowleri } & 0360 & & & & & $1 \mathrm{D}$ & & & \\
\hline & $\mathrm{MCM}$ & & & & \multirow{2}{*}{ N. pussardi } & EDF258 & & & \\
\hline & Northcott & & & & & NG260 & & & \\
\hline & Mst1 & & & & N. robinsoni & NG944 & & & \\
\hline & M4E & & & & \multirow{2}{*}{ N. schusteri } & CCAP1518/1F & & & \\
\hline & LEE & & & & & \begin{tabular}{|l|} 
NG325 \\
\end{tabular} & & & \\
\hline & KUL & & & & N. sturti & NG334 & & & \\
\hline & AR12 & & & & N. tenerifensis & TE3(37) & & & \\
\hline & $\mathrm{J} / 16 / 1 / 42 \mathrm{E}$ & & & & N. tihangensis & $\mathrm{T} 2 \mathrm{~A}$ & & & \\
\hline
\end{tabular}

Naegleria americana De Jonckheere, 2004; N. andersoni De Jonckheere, 1988; N. angularis De Jonckheere et Brown, 2005; N. antarctica De Jonckheere, 2004; N. australiensis De Jonckheere, 1981; N. byersi De Jonckheere, 2004; N. canariensis De Jonckheere, 2006; N. carteri Dobson, Robinson et Rowan-Kelly, 1997; N. chilensis De Jonckheere, Brown, Dobson, Robinson et Pernin, 2001; N. clarki De Jonckheere, 1994; N. dobsoni De Jonckheere, 2004; N. dunnebackei Visvesvara, De Jonckheere, Marciano-Cabral et Schuster, 2005; N. endoi De Jonckheere, 2004; N. fowleri Carter, 1970; N. fultoni De Jonckheere, Brown, Dobson, Robinson et Pernin, 2001; N. galeacystis De Jonckheere, 1994; N. gallica De Jonckheere, 2004; N. gruberi Schardinger, 1899; N. italica De Jonckheere, Pernin, Scaglia et Michel, 1984; N. indonesiensis De Jonckheere, Brown, Dobson, Robinson et Pernin, 2001; N. jadini Willaert et Le Ray, 1973; $N$. jamiesoni De Jonckheere, 1988; $N$. johanseni De Jonckheere, 2004; $N$. laresi De Jonckheere, 2004; N. lovaniensis Stevens, De Jonckheere et Willaert, 1980; N. martinezi De Jonckheere, 2004; N. mexicana De Jonckheere, 2004; N. minor De Jonckheere et Brown, 1995; N. morganensis Dobson, Robinson et Rowan-Kelly, 1997; N. niuginiensis Dobson, Robinson et Rowan-Kelly, 1997; N. pagei De Jonckheere, 2002; N. peruana* De Jonckheere; $N$. philippinensis** De Jonckheere, 2002; $N$. pringsheimi De Jonckheere, 2002; $N$. pussardi Pernin et De Jonckheere, 1996; N. robinsoni De Jonckheere et Brown, 1999; N. schusteri De Jonckheere, 2004; N. sturti Dobson, Robinson et Rowan-Kelly, 1997; N. tenerifensis De Jonckheere, 2006; N. tihangensis De Jonckheere, 2002.

* Species not defined formally, the name is first mentioned in GenBank for the sequence AJ785757.

**Species name first mentioned in Matias et al. (1991), after that as "in preparation" by De Jonckheere (2002) (strain RJTM). Sequences of another two strains are available in GenBank - Wikmark et al. (unpubl.).

The following eight species, Naegleria arctica, $N$. neoantarctica, $N$. neochilensis, $N$. neodobsoni, $N$. neopolaris, $N$. paradobsoni, $N$. polaris, and N. spitzbergenensis, had been named in GenBank but not formally published before this paper was accepted for print. Recently, these amoebae have been described as eight new species by De Jonckheere (2006). 
Table 2. Origin of fish-isolated Naegleria strains included in the study.

\begin{tabular}{|c|c|c|c|}
\hline $\begin{array}{l}\text { Strain/ } \\
\text { clone }\end{array}$ & Fish species and organ sampled & Local origin of fish & $\begin{array}{l}\text { Strain isolated/ } \\
\text { cloned }\end{array}$ \\
\hline BCZ4/I & $\begin{array}{l}\text { Bunocephalus coracoideus (Cope); } \\
\text { gills }\end{array}$ & upper Amazon River (import) & Feb 1999/Feb 1999 \\
\hline $\mathrm{CL} / \mathrm{I}$ & $\begin{array}{l}\text { Corydoras leucomelas Eigenmann et } \\
\text { Allen; brain }\end{array}$ & upper Amazon River (import) & Mar 2001/Dec 2002 \\
\hline $\mathrm{S} 1 \mathrm{Z} / \mathrm{I}$ & Esox lucius Linnaeus; gills & Rožmberk pond, Czech Rep. & Apr 1998/Feb 2002 \\
\hline $\mathrm{O} 3 \mathrm{Z} / \mathrm{I}$ & Perca fluviatilis Linnaeus; gills & Svět pond, Czech Rep. & Apr 1998/ Feb/ 2002 \\
\hline $4796 / \mathrm{I}$ & Rutilus rutilus Linnaeus; liver & Lužnice River, Czech Rep. & Nov 1991/May 1999 \\
\hline RR13Z/I & R. rutilus; gills & Novohradský pond, Czech Rep. & Feb 2000/May 2000 \\
\hline $4830 / \mathrm{I}$ & Salmo trutta fario Linnaeus; kidney & Liběchovka brook, Czech Rep. & Dec 1991/Jun 1997 \\
\hline RR11Z/I & Rutilus rutilus; gills & Novohaklovský pond, Czech Rep. & Feb 2000/Apr 2000 \\
\hline SUM3V/I & Silurus glanis Linnaeus; skin lesions & Elbe River tributary, Czech Rep. & May 2000/Feb 2002 \\
\hline GP3/III & $\begin{array}{l}\text { Gnathonemus petersii (Günther); } \\
\text { gills }\end{array}$ & Congo River (import) & Mar 2002/Apr 2002 \\
\hline $\mathrm{A} 22 / \mathrm{I}$ & Abramis brama (Linnaeus); liver & Vyšatov pond, Czech Rep. & Apr 1994/Sep 2004 \\
\hline $4564 / \mathrm{IV}$ & Perca fluviatilis; kidney & Černovický potok brook, Czech Rep. & Mar 1991/Jan 1995 \\
\hline $\mathrm{Pd} 72 \mathrm{Z} / \mathrm{I}$ & $\begin{array}{l}\text { Oncorhynchus mykiss (Walbaum); } \\
\text { gills }\end{array}$ & Černá farm, Czech Rep. & Apr 1998/May 1998 \\
\hline $\mathrm{CB} 2 \mathrm{~B} / \mathrm{I}$ & $\begin{array}{l}\text { Clarias batrachus (Linnaeus) hybrid; } \\
\text { brain }\end{array}$ & Thailand, Bangkok market & Nov 1997/Dec 1997 \\
\hline $\mathrm{CB} 1 \mathrm{~S} / \mathrm{I}$ & C. batrachus hybrid; spleen & Thailand, Bangkok market & Nov 1997/May 2005 \\
\hline $4709 / \mathrm{I}$ & Perca fluviatilis; spleen & Černovický potok brook, Czech Rep. & Jul 1991/Mar 1997 \\
\hline $\operatorname{Pd} 56 Z / I$ & Oncorhynchus mykiss; gills & Černá brook, Czech Rep. & Apr 1998/Jul 1998 \\
\hline $4177 / \mathrm{I}$ & Blicca bjoerkna (Linnaeus); brain & Dvořiště pond, Czech Rep. & May 1990/Mar 1997 \\
\hline
\end{tabular}

document morphological features of living amoebae. All clones were tested for production of temporary flagellated stages. The study of ultrastructure was an integral part of strain characterisation. Fixation and processing of material for electron microscopy followed procedures described elsewhere (Dyková et al. 2005).

\section{Molecular characterisation of strains under study}

Genomic DNA was extracted exclusively from clonal cultures of strains thoroughly washed to remove contaminating bacteria. When a relatively small amounts of cultured cells were available, the DNA was extracted using DNeasy ${ }^{\mathrm{TM}}$ Tissue Kit (Qiagen, Germany) according to instructions of the manufacturer. Phenol/chloroform extractions of cell lysates as described by Maslov et al. (1996) were used in six strains due to a large number of cells harvested. Sequences of SSU rDNA and ITS were used as diagnostic tools to identify fish-isolated Naegleria strains.

\section{SSU rRNA gene sequences}

The SSU rDNA was amplified by PCR using universal eukaryotic primers (forward ERIB1 5'-ACCTGGTTGATCCTG CCAG-3' and reverse ERIB10 5'-CTTCCGCTGGTTCACCT ACGG-3') (Barta et al. 1997). Approximately $50 \mathrm{ng}$ of genomic DNA template, $250 \mu \mathrm{M}$ of dNTPs, $10 \mathrm{pM}$ of each primer, $2.5 \mu 110 \times$ PCR buffer (Takara Bio, Otsu, Shiga,
Japan), and 1 unit of TaqDNA polymerase (Takara) were used in a $25-\mu 1$ reaction. The PCR amplification was performed with a thermal cycler T3 (Biometra Goettingen, Germany). The cycling conditions included an initial 5 min denaturation at $95^{\circ} \mathrm{C}$, then the SSU rRNA gene was amplified in 5 cycles $\left(94^{\circ} \mathrm{C} / 1 \mathrm{~min}, 44^{\circ} \mathrm{C} / 1.5 \mathrm{~min}\right.$, and $\left.72^{\circ} \mathrm{C} / 2 \mathrm{~min}\right)$ followed by 25 cycles $\left(94^{\circ} \mathrm{C} / 1 \mathrm{~min}, 48^{\circ} \mathrm{C} / 1.5 \mathrm{~min}\right.$ and $\left.72^{\circ} \mathrm{C} / 2 \mathrm{~min}\right)$ and a final extension at $72^{\circ} \mathrm{C} / 10 \mathrm{~min}$. The amplified products were gelpurified and cloned into $\mathrm{pCR}^{\circledR} 2.1$ TOPO cloning vectors (Invitrogen Carlsbad, California, USA) using the suggested protocol. Positive clones were sequenced in both directions using the CEQ DTCS Dye Kit (Beckman Coulter, Krefeld, Germany) with a combination of flanking and internal primers on an automatic sequencer CEQ ${ }^{\mathrm{TM}} 2000$ (Beckman Coulter).

\section{Internal transcribed spacer sequences}

The forward primer G-FOR 5'-GGGATCCGTTTCCGT AGGTGAACCTGC-3' and reverse G-REV 5'-GGGATCCAT ATGCTTAAGTTCAGCGGGT-3' (Coleman and Vacquier 2002) were used for the selective PCR amplification of the whole ITS region (ITS1, 5.8S, and ITS2). Except for primers, the other components of amplification mixture were the same as in the SSU rDNA amplification. The cycling conditions included an initial $5 \mathrm{~min}$ denaturation at $95^{\circ} \mathrm{C}$ followed by 30 cycles of amplification with a 1 min denaturing at $95^{\circ} \mathrm{C}$, a 2 
min annealing at $46^{\circ} \mathrm{C}$, a 1 min extension at $72^{\circ} \mathrm{C}$ and a final extension of $10 \mathrm{~min}$ at $72^{\circ} \mathrm{C}$.

\section{Sequence-based phylogenetic analyses}

To construct phylogenetic trees, the following sets of sequences were aligned using the Clustal_X program (Thompson et al. 1997) applying various alignment parameters.

a) SSU rRNA gene sequences of 18 fish-isolated Naegleria strains (Table 2) supplemented with all corresponding sequences of type and other strains of Naegleria species available in the GenBank database to date. Sequences of Vahlkampfia inornata and $V$. avara served as outgroup.

b) ITS sequences of fish-isolated Naegleria strains supplemented with corresponding sequences of selected Naegleria strains, which as well as fish-isolated strains are characterized by both ITS and SSU rDNA sequences. ITS sequences consisted of ITS1, 5.8S and a portion of ITS2. The most variable segment of sequences, the fourth stem-loop of ITS2, was excluded from alignment. The sequences of Naegleria andersoni, $N$. jamiesoni and $N$. minor served as outgroup because ITS sequences of $V$. inornata and $V$. avara differed substantially and could not be aligned with this data set.

c) Concatenated data set of the SSU rDNA and ITS sequences.

To estimate the intragenomic variation at ITS loci, a total of eight subcloned PCR products (two clones of each of four independent PCR products) from the same sample of DNA (extracted from clonal culture of Naegleria strain Pd72Z/I) were sequenced and compared.

Two types of analyses were conducted to assess phylogenetic relationships within Naegleria strains. Maximum parsimony method (MP) used as implemented in the program package PAUP*, version 4.0b10 (Swofford 2001) was done using heuristic search with random addition of taxa (10 replications). Gaps were treated as missing data. The MP analyses were performed using transition/transversion (Ts:Tv) ratio 1:2. The semistrict consensus tree was made from the resulting topologies. The confidence of branching was assessed using 1,000 bootstrap resamplings of the data sets.

Bayesian inference of phylogeny (BI) was estimated from concatenated SSU rDNA and ITS sequences using MrBayes programme (version 3.0) and Markov Chain Monte Carlo Methodology (MCMC) (Ronquist and Huelsenbeck 2003). BI was performed with parameters (rates $=$ invgamma, NST $=6$, ncat $=4)$ corresponding to the model $(G T R+I+\Gamma)$ estimated by MrModeltest v. 2.2 (Nylander et al. 2004). No a priori assumptions about the topology of the tree were made and all searches were provided with a uniform prior. The MCMC processes were set so that four chains were run simultaneously for 500,000 generations, with trees being sampled every hundredth for a total of 5,000 trees. Burn-in was determined when visual inspection indicated that the log-likelihood values achieved an asymptote over a large number of generations. The length of burn-in period was 100,000 generations.

Putative secondary structure prediction for ITS2 sequence of arbitrarily chosen fish-isolated strain was obtained using the programme Mfold version 3.2 (Zuker 2003). Sequences corresponding to the fourth stem-loop were then compared within the whole data set.

\section{RESULTS}

Safe assignment of fish-isolated strains to the genus Naegleria resulted from light and electron microscopic observations. All fish-isolated strains included in the study were able to transform to the flagellated stages and form cysts characteristic of Naegleria spp. The morphology of our set of strains was rather uniform. Subtle morphological and size differences of trophozoites of individual strains were not permanent. They were observed on a temporary basis, being provoked mostly by load of bacteria that especially in early phases of subculturing sometimes changed culture conditions. The clonal cultures of two strains (CB2B/I and CL/I) tolerated $37^{\circ} \mathrm{C}$, while two other strains (4564/IV and $4171 / \mathrm{I}$ ) were successfully grown at $30^{\circ} \mathrm{C}$. The latter two plus another two strains (4830/I, 4709/I) tolerated a wide range of temperatures $\left(6-30^{\circ} \mathrm{C}\right)$. The division of flagellated stages was not observed in any of our fishisolated strains.

\section{Sequence data}

Twelve new SSU rDNA sequences (DQ768714 to DQ768725) and 31 ITS sequences characterizing 18 fish-isolated Naegleria strains (DQ768726-DQ768743) were obtained in this study. The size of sequences and also presence or absence of the group I intron are summarized in Table 3. The lengths of SSU rDNA sequences range from 1,980 to $3,359 \mathrm{bp}$ within the set of 18 strains (Table 3 ). The GC content ranges from 44.26 to $47.99 \%$. The mean GC content in strains that have group I intron located within the SSU rRNA gene corresponds to 44.46 , in intronless strains to $47.74 \%$. Seventeen strains have identical length of ITS1 and 5.8S gene (33 and $175 \mathrm{bp}$, respectively). One only strain of this assemblage differs in having ITS1 34 bp long. The ITS2 sequences of fish-isolated strains are 100-207 bp in length. The set of strains with identical ITS1 and 5.8S is divided into eight subsets depending on identical ITS2 lengths (Table 3 ). Ten of 18 strains were found to have the group I intron located within the SSU rRNA gene.

\section{Phylogeny and taxonomy of fish-isolated Naegleria strains}

Congruent results predominated in the sequencebased phylogenetic analyses of our data sets (Figs. 1-4). The branching pattern, basically the same in all analyses performed, was supported with slightly different bootstrap values (higher values were computed in MP analysis of concatenated data for most nodes). Bayesian approach to estimate posterior probability of phylogeny based on concatenated sequences of SSU rDNA and ITS region (Fig. 4) supported branching pattern of MP analyses. The minimal lengths of branches characterizing the third clade of strains analysed in the study stressed their remarkable phylogenetic relatedness. 
Table 3. Fish-isolated Naegleria strains ordered by bp length of their ITS regions, with bp length of their SSU rDNA sequences and presence/absence of the group I intron.

\begin{tabular}{|c|c|c|c|c|c|c|}
\hline Strain/clone & ITS1 & $5.8 \mathrm{~S}$ & ITS2 & Total ITS & $\begin{array}{l}\text { SSU } \\
\text { rDNA }\end{array}$ & Intron \\
\hline CB2B/I & 33 & 175 & 100 & 308 & $1,980 *$ & - \\
\hline $4796 / \mathrm{I}$ & 34 & 175 & 106 & 315 & 2,011 & - \\
\hline $4830 / \mathrm{I}$ & 33 & 175 & 165 & 373 & 2,011 & - \\
\hline $\mathrm{A} 22 / \mathrm{I}$ & 33 & 175 & 165 & 373 & 2,011 & - \\
\hline $\mathrm{CL} / \mathrm{I}$ & 33 & 175 & 170 & 378 & 3,317 & + \\
\hline GP3/III & 33 & 175 & 170 & 378 & 3,317 & + \\
\hline $\mathrm{Pd} 72 \mathrm{Z} / \mathrm{I}$ & 33 & 175 & 170 & 378 & 3,285 & + \\
\hline $\mathrm{Pd} 56 \mathrm{Z} / \mathrm{I}$ & 33 & 175 & 170 & 378 & 3,285 & + \\
\hline $\mathrm{BCZ} 4 / \mathrm{I}$ & 33 & 175 & 177 & 385 & 3,318 & + \\
\hline S1Z/I & 33 & 175 & 185 & 393 & 2,013 & - \\
\hline $\mathrm{O} 3 \mathrm{Z} / \mathrm{I}$ & 33 & 175 & 185 & 393 & 2,013 & - \\
\hline RR11Z/I & 33 & 175 & 192 & 400 & 2,021 & - \\
\hline SUM3V/I & 33 & 175 & 192 & 400 & 3,359 & + \\
\hline $4177 / \mathrm{I}$ & 33 & 175 & 200 & 408 & $3,285^{*}$ & + \\
\hline 4564/IV & 33 & 175 & 200 & 408 & $3,285^{*}$ & + \\
\hline 4709/I & 33 & 175 & 200 & 408 & $3,285^{*}$ & + \\
\hline CB1S/I & 33 & 175 & 200 & 408 & 3,315 & + \\
\hline RR13Z/I & 33 & 175 & 207 & 415 & 2,021 & - \\
\hline
\end{tabular}

* Sequences reported in previous study (Dyková et al. 2001).

Phylogenetic analyses have divided Naegleria strains under study into three distinct clades (Figs. 1-4) regardless of data set utilized. When two Vahlkampfia species were used as outgroup (in MP analyses of SSU rDNA and concatenated sequences of SSU rDNA and ITS) the first, most basal and well-supported clade of analysed strains contained those representing $N$. minor, $N$. jamiesoni and N. andersoni.

The second, moderately supported clade contained strain-representatives of six named species of the genus (N. fowleri, N. martinezi, N. lovaniensis, N. sturti, $N$. niuginiensis, $N$. morganensis) and three fish-isolated strains. As documented in Figs. 1-4, i.e., in all analyses performed, strains RR13Z/I, RR11Z/I and SUM3V/I form a common, well-supported cluster of closely related strains. The lengths of ITS2 sequences differ in having $192 \mathrm{bp}$ in RR11Z/I and SUM3V/I, and $207 \mathrm{bp}$ in RR13Z/I (Table 3). The highly variable nucleotide sequence corresponding to the fourth stem-loop of ITS2 secondary structure is identical in strains RR11Z/I and SUM3V/I, while in RR13Z/I it matches $N$. dobsoni. Unfortunately, SSU rDNA sequence of $N$. dobsoni is not available.

All other fish-isolated strains branched within the third, most numerous clade that integrated 25 strains, subdivided into 6 clusters (Fig. 3). Their close relationships can be documented by the fact that the sequence similarity of two distant strains of this clade

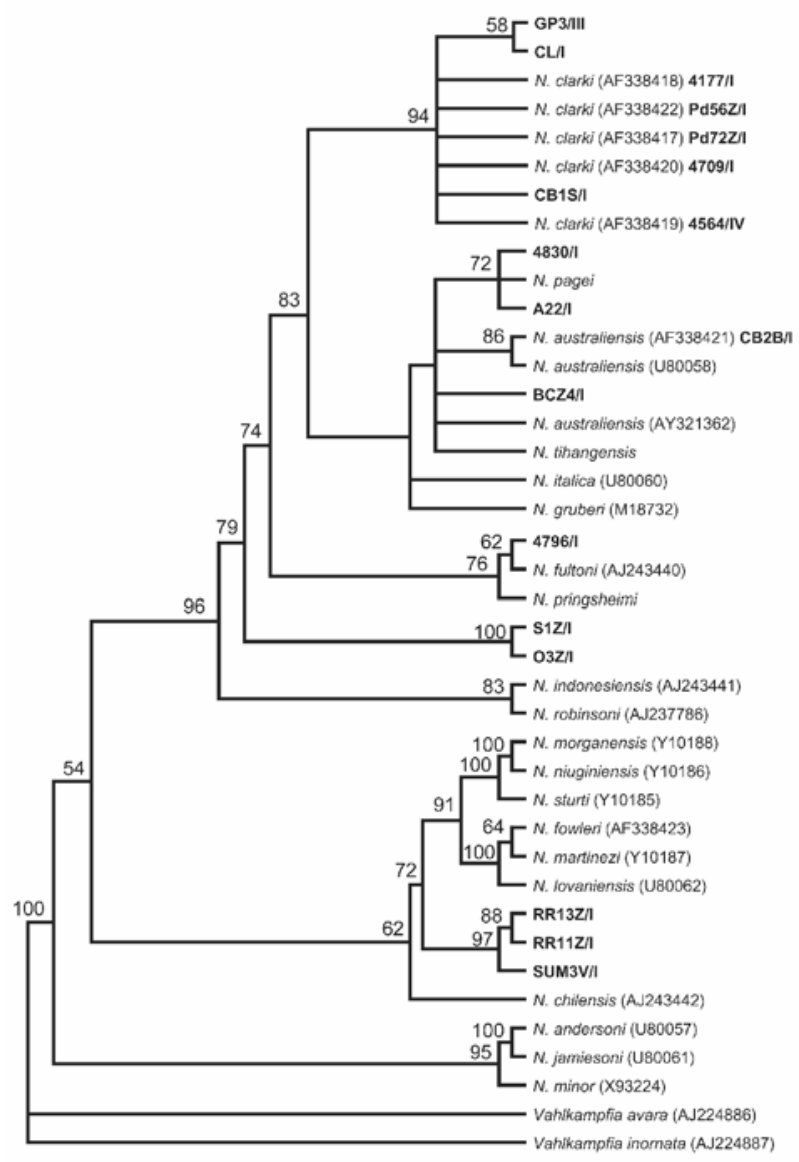

Fig. 1. Maximum parsimony tree (strict consensus of 132 trees) for SSU rDNA sequences from fish-isolated Naegleria strains (bold-faced) and strain-representatives of defined Naegleria species. Bootstrap values (1,000 replicates) are indicated for the nodes gaining more than $50 \%$ support. Vahlkampfia spp. were set as outgroup. GenBank accession numbers are in parentheses.

( $N$. robinsoni and $N$. australiensis) is much higher $(94.75 \%)$ than the similarity of most species within the first and second clade (e.g., N. jamiesoni and N. minor reveal $89.04 \%$ similarity).

The cluster "a" with basal position within the third clade contains only sequences of $N$. robinsoni and $N$. indonesiensis. Newly characterized fish-isolated strains S1Z/I and O3Z/I form cluster "b". They have the same lengths of ITS sequences as recorded in N. americana and also identical is the sequence of the fourth stemloop in secondary structure of ITS2. The sequence of SSU rDNA of $N$. americana is not available.

Strain 4796/I together with strains representing $N$. fultoni and N. pringsheimi form cluster " $\mathrm{c}$ ". The former strain, unique in our assemblage because of the length of ITS1 (34 bp), has the whole ITS sequence as well as the fourth stem-loop in the secondary structure of ITS2 identical with $N$. fultoni.

Closely related fish-isolated strains 4830/I and A22/I join the strain of $N$. pagei, forming cluster "d". Their 


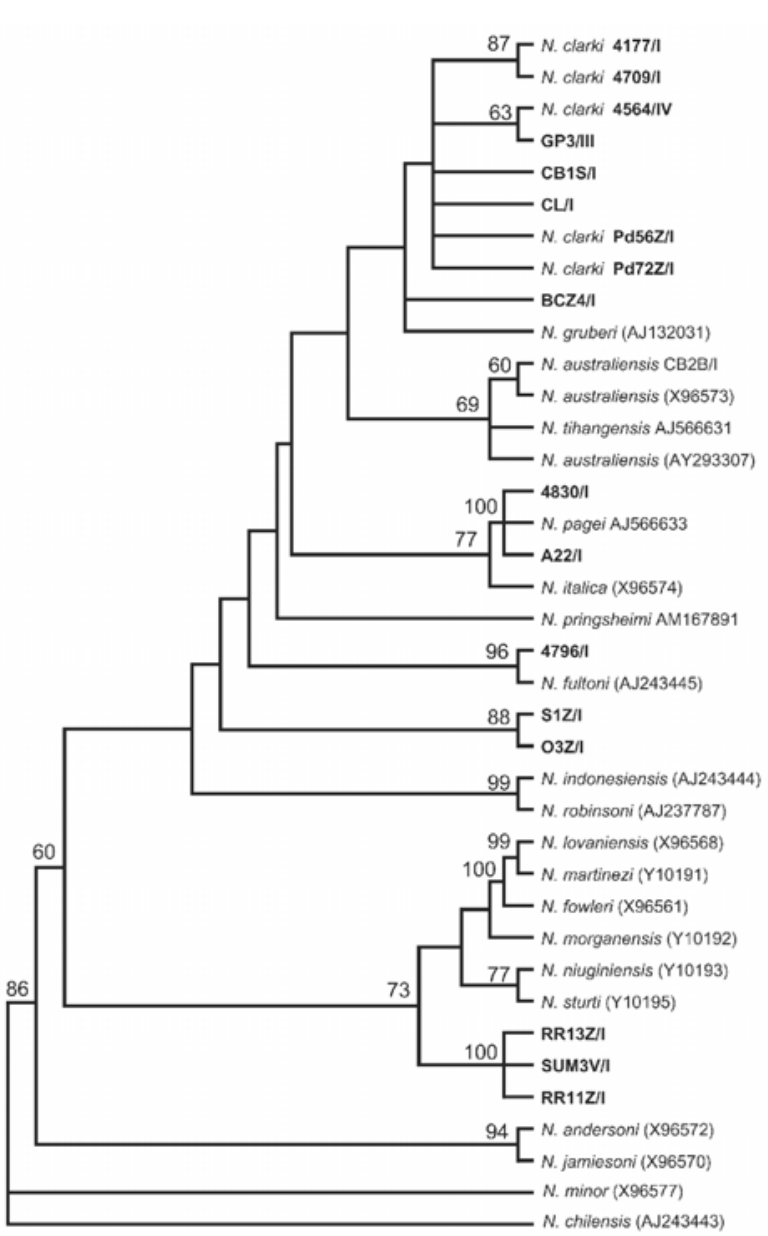

Fig. 2. Maximum parsimony tree (strict consensus of two trees) for ITS sequences of fish-isolated Naegleria strains (bold-faced) and strain-representatives of defined Naegleria species. Bootstrap values (1,000 replicates) are indicated for the nodes gaining more than $50 \%$ support. GenBank accession numbers are in parentheses.

close phylogenetic relationship documented in Figs. 1-4 is supported by the sequence identity in fourth stemloop of the secondary structure of ITS2.

Due to unstable phylogenetic position of strain BCZ4/I, its relatedness to defined Naegleria species was difficult to infer from analyses performed in this study. Nevertheless, the length of ITS2, unique among 48 named Naegleria species (of which 8 have been named in GenBank only but not formally published yet), is worth mentioning.

Three strain-representatives of $N$. australiensis together with $N$. tihangensis form cluster "e". The previous assignment of fish-isolated strain $\mathrm{CB} 2 \mathrm{~B} / \mathrm{I}$ to $N$. australiensis, which was based on phylogenetic analysis of SSU rDNA sequences, has been confirmed in this study. In addition to identity of ITS sequences, also the sequence of the fourth stem-loop in secondary structure of ITS2 was found identical with $N$. australiensis.

The sixth cluster ('f') contains eight fish-isolated strains, among them three newly introduced (GP3/III, $\mathrm{CL} / \mathrm{I}$ and $\mathrm{CB} 1 \mathrm{~S} / \mathrm{I}$ ) and five that on the basis of SSU
Dyková et al.: Phylogeny of fish-isolated Naegleria strains
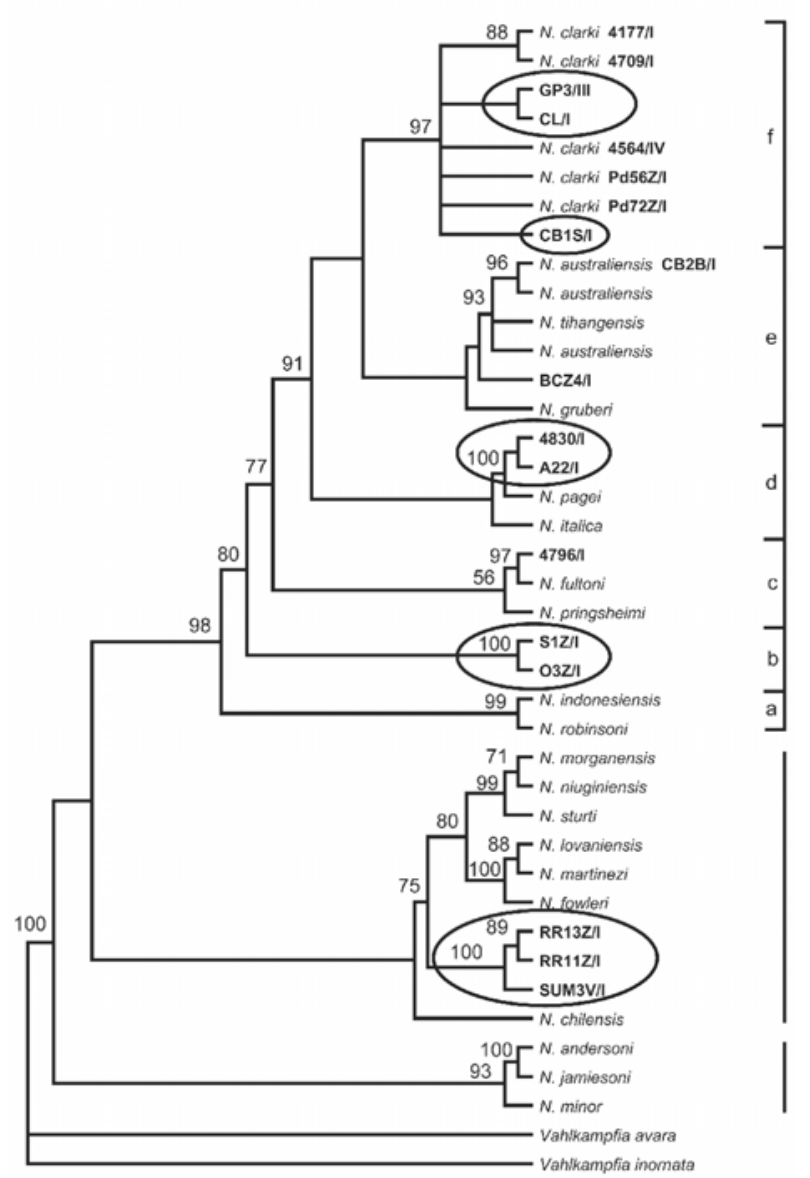

Fig. 3. Maximum parsimony tree (strict consensus of 13 trees) that includes the concatenated SSU rDNA and ITS sequences of fish-isolated Naegleria strains (bold-faced) and strainrepresentatives of defined Naegleria species. Bootstrap values (1,000 replicates) are indicated for the nodes gaining more than $50 \%$ support. Vahlkampfia spp. were set as outgroup. GenBank accession numbers are in Figs. 1 and 2.

rDNA sequences were assigned previously to $N$. clarki (Dyková et al. 2001). Their SSU rDNA sequences were supplemented with sequences of ITS region in this study. Strains of this cluster changed their mutual position depending on data set of sequences analysed. Strains GP3/III, CL/I, Pd72Z/I and Pd56Z/I have identical lengths of ITS1 and 5.8S and ITS2, the same as in $N$. canariensis, $N$. dunnebackei and $N$. gallica. The relatedness of this group of strains is reflected in identity of sequences of the fourth stem-loop in the ITS2 secondary structure. Unfortunately, SSU rDNA sequences of $N$. canariensis, $N$. dunnebackei and $N$. gallica are not available. ITS sequences of strains CB1S/I, 4177/I, 4709/I and 4564/IV that branch within cluster " $\mathbf{f}$ " are of the same length and identical with ITS sequence of reference strain of $N$. clarki (RU30).

Only eight fish-isolated strains could be assigned to species already defined, if both criteria, the recent ITS approach in defining Naegleria species (De Jonckheere 2004) and SSU rDNA sequence data were applied. 


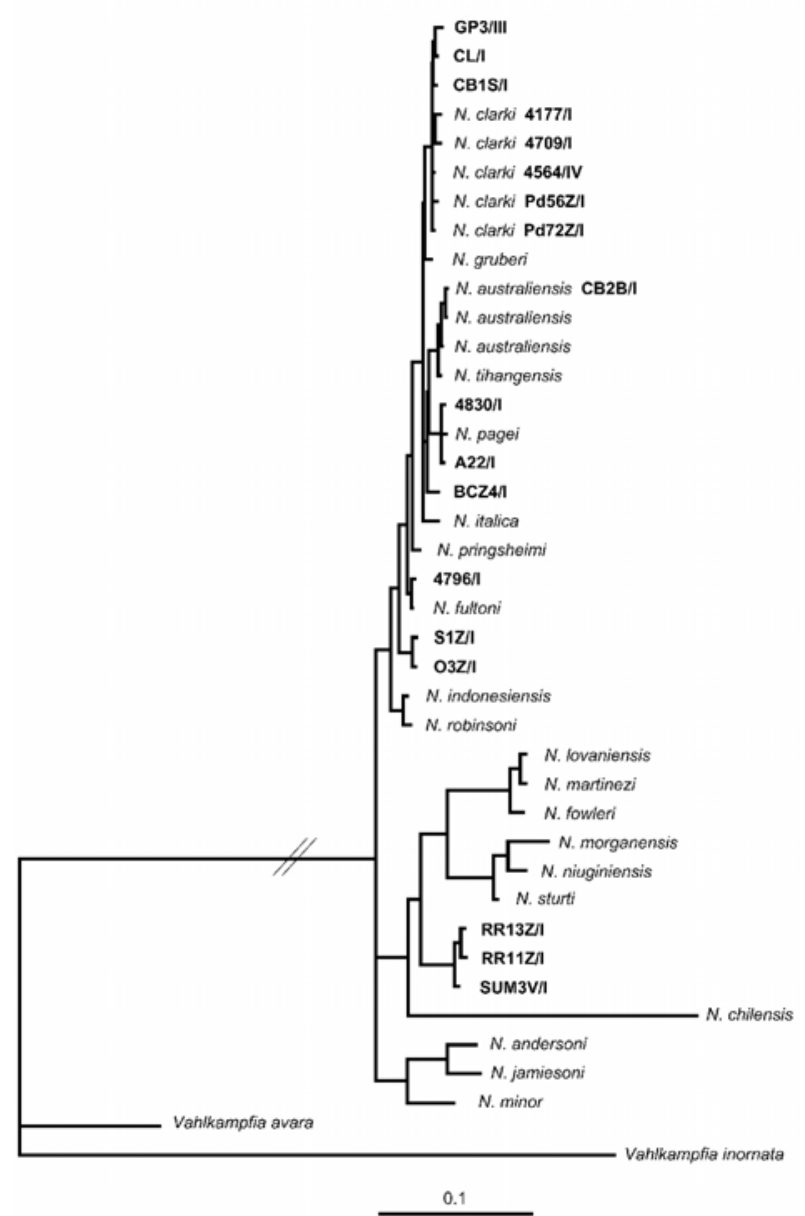

Fig. 4. Molecular phylogeny of tish-isolated Naegleria strains (bold-faced) and strain-representatives of defined Naegleria species (including Vahlkampfia spp. as outgroup) inferred from Bayesian analysis of the combined data (SSU rDNA and ITS sequences) using general-time-reversible model of nucleotide substitution. The branch leading to Naegleria spp. was shortened six times to demonstrate branching pattern within the third clade consisting of sequences of 25 strains.

Strain CB2B/I could be identified with $N$. australiensis; strains 4830/I and A22/I with $N$. pagei, strain 4796/I with $N$. fultoni and strains CB1S/I, 4177/I, 4709/I and 4564/IV with $N$. clarki.

\section{Intragenomic variation of ITS}

The comparison of ITS sequences obtained from the eight subcloned PCR products (two clones of each of four PCR products from the same sample of DNA extracted from clonal culture of the fish isolated strain) revealed nucleotide diversity ranging from 0 to $8 \mathrm{bp}$ substitutions (the sequence data are available on request).

\section{DISCUSSION}

The aim of the present study, i.e., possible identification of fish-isolated Naegleria strains with species already defined, using the novel data obtained in this study and data recorded before, could not be fully accomplished. However, several topics related to molecular taxonomy of Naegleria species worth discussing resulted from this study.

Because of a rather uniform morphology, the introduction of molecular approaches became of fundamental importance in the history of species definitions within the genus Naegleria Alexeieff, 1912 (De Jonckheere 1994, 1998, 2002, 2004, Pélandakis et al. 2000).

The SSU rRNA gene-derived phylogeny was used as a basis for improvements in taxonomy of many eukaryotic genera and for assessment of relatedness of organisms at higher taxonomic levels as well. However, the evolutionary conserved nature of these genes that makes them relatively uninformative at the generic and species levels in eukaryotes has been stressed several times (Sogin 1991, Coleman et al. 1998, Sogin and Silberman 1998, Pélandakis et al. 2000). The spacer regions of nuclear ribosomal genes have generally been found more variable and useful in comparing closely related species or populations (Felleisen 1997, De Jonckheere 1998, Pélandakis et al. 2000).

Since the time that sequences of genes were introduced to taxonomy, the question of "how much of a difference in base pairs of these sequences justifies recognition of a new species" has undoubtedly been asked and discussed many times. The answer given by De Jonckheere (2004) was, contrary to inconclusive outcomes of such discussions or analyses, concrete and taken as the usable rule in defining Naegleria species (Visvesvara et al. 2005). The currently accepted molecular definition of species within the genus Naegleria is primarily based on differences in the $5.8 \mathrm{~S}$ and ITS sequences, but it is ITS2 sequence that defines species among the strains that have identical ITS1 and 5.8S: "any strain that has an ITS2 sequence that differs by more than one nucleotide bp can be considered as another species" (De Jonckheere 2004).

Out of 40 Naegleria species introduced with names to date, 22 were characterized by sequences of SSU rDNA with 15 of them, in addition, also by sequences of ITS. Definitions of 18 Naegleria species published to date plus another 8 named species whose existence has so far only been announced in GenBank (see Table 1) are based on ITS sequences only.

ITS2 sequences of several defined species actually differ in two nucleotide bp, (e.g., $N$. canariensis and $N$. gallica that have the same length of ITS2 sequence, or $N$. australiensis and $N$. tihangensis that differ just in two nucleotide bp that at the same time increase the length of ITS2). Two strains (N280 and AB-T-F3) recorded in GenBank as representatives of two species (N. peruana and $N$. italica) have absolutely identical ITS sequences. Minute differences in ITS2 sequences can be demonstrated in strains assigned to the same species: in one (NG434) out of three strains of $N$. byersi, and in one (A2) out of six strains of $N$. andersoni, the ITS2 se- 
quences differ in one nucleotide bp. Pronounced differences (up to $8 \mathrm{bp}$ ) were found in sequences of subcloned PCR products from one sample of DNA of our fishisolated strain.

Problems encountered in comparing nucleotide bp differences or genetic distances while intending to delineate species have usually been concluded by the statement that from purely taxonomic standpoint no established criteria exist to recognise species on the basis of nucleotide sequence data. For this reason, divergent sequences or genetic distances between analysed organisms must be interpreted with caution, as stressed by Sogin $(1990,1991)$ especially for protozoans.

When species concepts were analysed in relation with parasites, the hope was expressed that the habit to identify new species just on the basis of a certain number of base changes within the spacer sequences of rDNA will stop and the search for new criteria for species definitions will continue according to requirements of different phyla (Kunz 2002).

Since we felt that the potential power of SSU rDNA sequences has not been fully exploited in taxonomy of Naegleria and the information obtained on variations in the ITS sequences of subcloned PCR products of the same sample of DNA (strain Pd72Z/I) contravened De Jonckheere's (2004) guidelines for Naegleria species definition, we have tried to combine SSU rDNA and ITS sequence data. Unfortunately, heterogeneity in molecular characterisation of Naegleria species, i.e., the lack of corresponding SSU rDNA and ITS sequences, did not allow analysis of more than 38 Naegleria strains, which represent only half of the defined (named) species.

The predominating congruence of phylogenetic relationships found within three data sets of Naegleria se- quences was a promising result of this study, but in the light of the number of defined species it still is not convincing enough for us to restrict definition of new species to phylogenetic analysis of relatively short ITS regions.

Considering the degree of sequence similarity of strain-representatives of many denominated Naegleria species on the one hand and the intragenomic variations of ITS sequences established in our screening on the other, one can expect that criteria for species definitions might require a re-evaluation in the future. The intragenomic as well as interstrain polymorphism exhibited at ITS loci should be clarified using goal-directed selection of strains, i.e., using samples of DNA from clonal cultures of type or reference strains of phylogenetically close as well as distantly related species. The range of ITS sequence variation should be estimated also for strain-representatives of the presumably same species reported from far distant localities. In addition, direct sequencing of PCR products and comparison of sequences with those obtained from subcloned PCR products might be useful in striving for relevant molecular markers of species within the genus Naegleria.

The data accumulated on ITS sequences of Naegleria strains are of a great value; nevertheless, we think they should not be taken as the exclusive markers of species boundaries. In the future, they could characterise types of ITS sequences within species redefined on the basis of multiple gene analysis.

Acknowledgements. This study was supported by research projects of the Institute of Parasitology, Biology Centre, Academy of Sciences of the Czech Republic (Z60220518 and LC 522) and by the Ministry of Education, Youth and Sports (project No. MSM6007665801).

\section{REFERENCES}

BARTA J.R., MARTIN D.S., LIBERATOR P.A., DASHKEVICZ M., ANDERSON J.W., FEIGHNER S.D., ELBRECHT A., PERKINS-BARROW A., JENKINS M.C., DANFORTH H.D., RUFF M.D., PROFOUS-JUCHELKA H. 1997: Phylogenetic relationships among eight Eimeria species infecting domestic fowl inferred using complete small subunit ribosomal DNA sequences. J. Parasitol. 83: 268-271.

COLEMAN A.W., PREPARATA R.M., MEHROTRA B., MAI J.C. 1998: Derivation of the secondary structure of the ITS-1 transcript in Volvocales and its taxonomic correlations. Protist 149: 135-146.

COLEMAN A.W., VACQUIER V.D. 2002: Exploring the phylogenetic utility of ITS sequences for animals: a test case for abalone (Haliotis). J. Mol. Evol. 54: 246-257.

ČERVA L. 1969: Axenic culture of Naegleria. Science 163: 576.
DE JONCKHEERE J.F. 1994: Comparison of partial SSU rDNA sequences suggests revision of species names in the genus Naegleria. Eur. J. Protistol. 30: 333-341.

DE JONCKHEERE J.F. 1998: Sequence variation in the ribosomal internal transcribed spacers including the $5.8 \mathrm{~S}$ rDNA of Naegleria spp. Protist 149: 221-228.

DE JONCKHEERE J.F. 2002: A century of research on the amoeboflagellate genus Naegleria. Acta Protozool. 41: 309-342.

DE JONCKHEERE J.F. 2004: Molecular definition and the ubiquity of species in the genus Naegleria. Protist 155 : 89-103.

DE JONCKHEERE J.F. 2006: Isolation and molecular identification of free-living amoebae of the genus Naegleria from Arctic and sub-Antarctic regions. Eur. J. Protistol. 42: 115-123. 
DYKOVÁ I., KYSELOVÁ I., PECKOVÁ H., OBORNÍK M., LUKEŠ J. 2001: Identity of Naegleria strains isolated from organs of freshwater fishes. Dis. Aquat. Org. 46: $115-121$.

DYKOVÁ I., LOM J. 2004: Advances in the knowledge of amphizoic amoebae infecting fish. Folia Parasitol. 51: 8197.

DYKOVÁ I., VEVERKOVÁ-FIALOVÁ M., FIALA I., DVOŘÁKOVÁ H. 2005: Protacanthamoeba bohemica sp. n., isolated from the liver of tench, Tinca tinca (Linnaeus, 1758). Acta Protozool. 44: 369-376.

FELLEISEN R.S.J. 1997: Comparative sequence analysis of 5.8S rRNA genes and internal transcribed spacer (ITS) regions of trichomonadid protozoa. Parasitology 115: 111119.

KUNZ W. 2002: When is a parasite species a species? Trends Parasitol. 18: 121-124.

MASLOV D.A., LUKEŠ J., JIRKU M., SIMPSON L. 1996: Phylogeny of trypanosomes as inferred from the small and large subunit rRNAs: implications for the evolution of parasitism in the trypanosomatid protozoa. Mol. Biochem. Parasitol. 75: 197-205.

MATIAS R., ENRIQUEZ G., NATIVIDAD F. 1991: Cell biology of the Philippine amoeboflagellate Naegleria philippinensis. Trans. Natl. Acad. Sci. Technol. 13: 439 444.

NYLANDER J.A.A., RONQUIST F., HUELSENBECK J.P., NIEVES-ALDREY J.L. 2004: Bayesian phylogenetic analysis of combined data. Syst. Biol. 53: 47-67.

PÉLANDAKIS M., SERRE S., PERNIN P. 2000: Analysis of the 5.8S rRNA gene and the internal transcribed spacers in Naegleria spp. and in N. fowleri. J. Eukaryot. Microbiol. 47: 116-121.
RONQUIST F., HUELSENBECK J.P. 2003: MrBayes 3: Bayesian phylogenetic inference under mixed models. Bioinformatics 19: 1572-1574.

SOGIN M.L. 1990: Amplification of ribosomal RNA genes for molecular evolution studies. In: M.A. Iunis, D.H. Gelfand, J.J. Sninsky and T.J. White (Eds.), PCR Protocols: A Guide to Methods and Applications. Academic Press, San Diego, California, pp. 307-314.

SOGIN M.L. 1991: The phylogenetic significance of sequence diversity and length variations in eukaryotic small subunit ribosomal RNA coding regions. In: L. Warren, H. Koprowski (Eds.), New Perspectives on Evolution. Plenum Press, Wiley-Liss, New York, pp. 175-188.

SOGIN M.L., SILBERMAN J.D. 1998: Evolution of the protists and protistan parasites from the perspective of molecular systematics. Int. J. Parasitol. 28: 11-20.

SWOFFORD D.L. 2001: PAUP*: Phylogenetic Analysis Using Parsimony (*and other methods). Version 4.0b10. Sinauer Associates, Sunderland, Massachusetts, USA.

THOMPSON J.D., GIBSON T.J., PLEWNIAK F., JEANMOUGIN F., HIGGINS D.G. 1997: The CLUSTAL_X windows interface: flexible strategies for multiple sequence alignment aided by quality analysis tools. Nucl. Acids Res. 25: 4876-4882.

VISVESVARA G.S., DE JONCKHEERE J.F., MARCIANOCABRAL M., SCHUSTER F.L. 2005: Morphologic and molecular identification of Naegleria dunnebackei $\mathrm{n}$. sp. isolated from a water sample. J. Eukaryot. Microbiol. 52: 523-531.

ZUKER M. 2003: Mfold web server for nucleic acid folding and hybridization prediction. Nucl. Acids Res. 31: 34063415.

Accepted 10 July 2006 